\title{
TNF receptor-associated factor 5 gene confers genetic predisposition to acute anterior uveitis and pediatric uveitis
}

Qin Xiang ${ }^{1 \dagger}$, Lu Chen ${ }^{1 \dagger}$, Jing Fang ${ }^{1}$, Shengping Hou' ${ }^{1}$ Lin Wei ${ }^{1}$, Lin Bai ${ }^{1}$, Yunjia Liu', Yan Zhou' ${ }^{1}$ Aize Kijlstra ${ }^{2}$ and Peizeng Yang ${ }^{1 *}$

\begin{abstract}
Introduction: TNF Receptor-Associated Factor 5 (TRAF5) has been shown to be associated with autoimmune disease. The current study sought to investigate the potential association of TRAF5 with acute anterior uveitis (AAU) and pediatric uveitis in Han Chinese.

Methods: Three TRAF5 SNPs were analyzed in 450 AAU patients with or without ankylosing spondylitis (AS), 458 pediatric uveitis patients, and 1,601 healthy controls by using polymerase chain reaction-restriction fragment length polymorphism (PCR-RFLP) or TaqMan SNP Genotyping Assay. Numerous variables were evaluated, including age, sex distribution, and clinical and laboratory observations.

Results: Two SNPs (rs6540679, rs12569232) of TRAF5 were associated with pediatric uveitis, and rs12569232 also showed a relation with the presence of microvascular leakage. No significant associations were found when patients were subdivided according to their rheumatoid factor (RF) or anti-nuclear antibody (ANA) status or whether they had juvenile idiopathic arthritis (JIA). Rs12569232 predisposed to AAU and its subgroups (with ankylosing spondylitis (AS) or HLA-B27 positive). No association was found between rs 10863888 and either pediatric uveitis or AAU.

Conclusion: This study revealed that TRAF5 is involved in the development of AAU and pediatric uveitis. Further stratified analysis according to the clinical and laboratory observations suggested that rs12569232/TRAF5 may play a role in the development of retinal vasculitis.
\end{abstract}

\section{Introduction}

Uveitis is a manifestation of complex processes and a major etiologic factor of visual loss. Uveitis can be categorized into several phenotypes. Among them, acute anterior uveitis (AAU) is the most common entity encountered [1]. Many patients with AAU are HLA-B27 positive, and a strong association with ankylosing spondylitis (AS) is observed in this subgroup of patients [2,3]. Similarly, $30 \%$ to $50 \%$ of patients with HLA-B27-positive AS will have an episode of AAU in the course of their disease [4-6]. Both heredity and environmental factors, especially bacterial triggers, are thought to be involved in the

\footnotetext{
* Correspondence: peizengycmu@126.com

${ }^{\dagger}$ Equal contributors

'The First Affiliated Hospital of Chongqing Medical University, Chongqing Key Laboratory of Ophthalmology and Chongqing Eye Institute, Chongqing 400016, PR China

Full list of author information is available at the end of the article
}

development of AAU and AS [7-9]. Half of the AAU cases are HLA-B27 positive [8], and the association of HLA-B27 with AS is found in almost all ethnic groups [10-13].

Pediatric uveitis is one of the most common reasons for childhood blindness. Children with uveitis comprise $2.2 \%$ to $10.6 \%$ of the total number of uveitis patients $[14,15]$, and anterior uveitis is the most frequent type of involvement in the majority of cases [16,17]. About $60 \%$ of pediatric uveitis cases are diagnosed as idiopathic uveitis, followed by juvenile idiopathic arthritis (JIA)-associated anterior uveitis [17]. Rheumatoid factor (RF), anti-nuclear antibody (ANA), and fundus fluorescein angiography (FFA) are regarded as important tests for pediatric uveitis and JIA.

Recent years witnessed a rapid improvement in the understanding of the genetic basis of AS, AAU and pediatric uveitis, including more than 69 subtypes of HLA-B27, as well as other immune-response genes, such

\section{Ciomed Central}


as $I L-1 A, E R A P 1, I L-23 R$ in AS [18], TLR2, TLR4, TNF in AAU $[19,20]$, and chemokine and chemokine-receptor genes in pediatric uveitis [21]. The involvement of these latter genes is, however, not consistent among the various ethnic groups throughout the world, as evidenced by association studies concerning $I L-23 R$ in AS [22-24], and further studies in well-defined ethnic populations are needed to understand how non-HLA-B27 genes can contribute to the development of autoimmune or autoinflammatory diseases.

TNF receptor-associated factor 5 (TRAF5) is a signal transducer that links members of the tumor necrosis factor (TNF)-receptor family to different signaling pathways, regulating NF- $\mathrm{KB}$ and probably JNK activation [25-27]. $N F-k B$ is considered a common transcription factor that is critical for innate and adaptive immunity and has been implied to play a role in autoimmune and autoinflammatory diseases, such as JIA [28], rheumatoid arthritis [29], and AS [30]. Inhibition of NF- $k B$ has been verified as a treatment for AAU, experimental autoimmune encephalomyelitis, experimental autoimmune uveitis and inflammatory arthritis [31-34]. Recent studies have shown that TRAF5 polymorphisms are associated with rheumatoid arthritis (RA) [35]. As mentioned earlier, uveitis and arthritis have overlapping manifestations, and because the relation between TRAF5 with uveitis has not yet been reported, we decided to investigate the role of TRAF5 polymorphisms in two forms of uveitis, AAU and pediatric uveitis.

\section{Methods}

\section{Subjects}

The study included 450 AAU patients, 458 pediatric uveitis patients, and 1,601 healthy adult controls. All patients and controls were Han Chinese, as confirmed by their ID cards. The diagnosis of AS was based on the modified New York criteria [36], and AAU patients were diagnosed principally according to clinical manifestations [37,38]. Pediatric uveitis was defined as uveitis first seen in patients younger than 16 years. Children with Behçet disease, Vogt-Koyanagi-Harada syndrome, or definite infectious uveitis entities were excluded from the study. JIA was defined as arthritis of at least 6 weeks' duration without any other identifiable cause in children younger than 16 years. Subjects were excluded if they had Behçet disease, Vogt-Koyanagi-Harada syndrome, or another type of uveitis. Blood samples of the patients and controls were obtained from the Uveitis Study Center of the Sun Yat-sen University (Guangzhou, P.R. China) and the First Affiliated Hospital of Chongqing Medical University (Chongqing, P.R. China) between 2005 and 2013. All the subjects participating in our study came from all over the country, as evidenced by their ID cards. The study was approved by the Local Ethics Research Committee of The First Affiliated
Hospital of Chongqing Medical University, Chongqing, China (Permit Number: 2009-201008), and all tested subjects gave their written informed consent; for children, the informed consent was obtained from their parents or guardians. The procedures followed the tenets of the Declaration of Helsinki.

\section{Clinical and laboratory observations}

Pediatric uveitis patients underwent a uveitis screening protocol encompassing ANA $(n=176$; positive rate was $17.0 \%), \operatorname{RF}(n=187$; positive rate was $15.5 \%)$, and FFA ( $n=271$; microvascular leakage rate detected by FFA was found in $63.5 \%$ of tested patients). An ANA titer above 1:100 and an RF level above $20.0 \mathrm{IU} / \mathrm{ml}$ were considered positive. FFA was considered a positive result when dye leakage from a retinal vessel was observed. Of the AAU patients, 209 had AS, and of the 332 subjects tested for HLA-B27, 267 (80.4\%) were positive. All these tests were performed in the First Affiliated Hospital of Chongqing Medical University (Chongqing, P.R. China). The clinical characteristics of the patients are shown in Tables 1 and 2 .

\section{SNP selection, DNA extraction, and genotyping}

The polymorphisms used in this study were based on earlier reports in RA [35], including rs6540679, rs7514863, rs12569232, and rs10863888. Genomic DNA samples of patients and healthy controls were extracted by using the QIAamp DNA Blood Mini Kit (Qiagen, Valencia, CA, USA) and genotyped by polymerase chain reactionrestriction fragment length polymorphism (PCR-RFLP) for rs6540679 or by TaqMan SNP Genotyping Assay for rs12569232 (TaqMan assay ID: C_26176827_20) and rs10863888 (TaqMan assay ID: C_26176858_10) using the ABI 7500 Real-Time PCR system. Digestion PCR products were visualized on a $4 \%$ agarose gel and stained with GoldViewTM (SBS Genetech, Beijing, China). Unfortunately, as we designed six PCR primers for rs7514863, none of their PCR product was satisfactory to go to the digestion step. No TaqMan SNP Genotyping Assay for it

Table 1 Clinical features of the investigated AAU patients

\begin{tabular}{lll}
\hline Clinical features & $\boldsymbol{n}$ (total $=\mathbf{4 5 0})$ & $\boldsymbol{\%}$ \\
\hline Age (years) & $39.2 \pm 10.0$ & \\
Male & 314 & 69.8 \\
Female & 136 & 30.2 \\
Uveitis & 450 & 100 \\
AAU patients with AS & 209 & 46.4 \\
AAU patients without AS & 241 & 53.6 \\
HLA-B27(+) & $267(332$ tested) & 80.4 \\
HLA-B27(-) & $65(332$ tested) & 19.6 \\
\hline
\end{tabular}

$\mathrm{AAU}$, acute anterior uveitis; $\mathrm{AS}$, ankylosing spondylitis. + , having this feature; - , not having this feature. 
Table 2 Clinical features of the investigated pediatric uveitis patients

\begin{tabular}{lll}
\hline Clinical features & \multicolumn{2}{c}{ Pediatric uveitis } \\
\cline { 2 - 3 } & $\boldsymbol{n}$ (total = 458) & \% \\
\hline Age at onset (years \pm SD) & $9.0 \pm 4$ & 46.7 \\
Male & 214 & 53.3 \\
Female & 244 & 100 \\
Uveitis & 458 & 13.1 \\
Pediatric uveitis with JIA & 60 & 63.5 \\
FFA(+) & $172(271$ tested) \\
ANA(+) & $30(176$ tested) & 17.0 \\
RF $(+)$ & $29 \mathrm{~b}(187$ tested) & 15.5 \\
\hline
\end{tabular}

JIA, juvenile idiopathic arthritis; FFA, fundus fluorescein angiography; ANA, anti-nuclear antigen; RF, rheumatoid factor. +, having this feature; -, not having this feature.

is available, we had to give up this SNP, although it was found to have been significantly associated with RA.

All the tests were performed according to the manufacturers' instructions. Direct sequencing was also performed by the Beijing Biomed Co., Ltd (Beijing, China), by using randomly selected subjects ( $10 \%$ of all samples) to validate the method used in this study.

\section{Statistical analysis}

Test of Hardy-Weinberg equilibrium (HWE), evaluation of genotype and allele frequencies, and calculation of odds ratios (ORs) and 95\% confidence intervals (95\% CIs) were done by following the method of Chen et al. [39]. The $P$ values were corrected $\left(P_{\mathrm{c}}\right)$ by using the Bonferroni correction method. $P_{\mathrm{c}}<0.05$ was considered significant. The linkage disequilibriums (LDs) of these tested SNPs were compared by using Haploview v3.32.

\section{Results}

TRAF5 gene implicated in susceptibility to acute anterior uveitis

The three SNPs (rs6540679, rs12569232, rs10863888) of TRAF5 were successfully genotyped and conformed to Hardy-Weinberg expectation in controls. The chosen SNPs were not in linkage disequilibrium with each other.

The frequencies of the CG genotype and C allele of rs12569232 in the AAU group were much lower than those in the healthy controls $\left(P_{\mathrm{c}}=7.43 \times 10^{-10}\right.$; OR, 0.283; $P_{\mathrm{c}}=2.12 \times 10^{-9}$; OR, 0.346 respectively) whereas the frequencies of the GG genotype $\left(P_{\mathrm{c}}=7.44 \times 10^{-10}\right.$, OR 3.314) and $G$ allele were significantly higher (Table 3 ). Further analysis was done in the following four subgroups: AAU with $\mathrm{AS}\left(\mathrm{AAU}^{+} \mathrm{AS}^{+}\right)$, AAU without AS $\left(\mathrm{AAU}^{+} \mathrm{AS}^{-}\right)$, HLAB27-positive AAU $\left(\mathrm{AAU}^{+} \mathrm{B} 27^{+}\right)$, and HLA-B27-negative AAU $\left(\mathrm{AAU}^{+} \mathrm{B} 27^{-}\right)$. Our data revealed that the associated polymorphisms of rs12569232/TRAF5 were consistent among the AAU subgroups investigated (Table 4). We failed to
Table 3 Genotype and allele frequency analysis between TRAF5 polymorphisms in AAU patients and healthy controls

\begin{tabular}{|c|c|c|c|}
\hline SNP & $\begin{array}{l}\text { AAU } \\
(n=450)\end{array}$ & $\begin{array}{l}P_{c} \\
\text { (OR) }\end{array}$ & $\begin{array}{l}\text { Control } \\
(n=1,601)\end{array}$ \\
\hline \multicolumn{4}{|c|}{ rs12569232 } \\
\hline $\mathrm{CC}$ & 4 & NS & 20 \\
\hline CG & 28 & $7.43 \times 10^{-10}(0.283)$ & 304 \\
\hline GG & 418 & $7.44 \times 10^{-10}(3.314)$ & 1,277 \\
\hline C & $4.0 \%$ & $2.12 \times 10^{-9}(0.346)$ & $10.7 \%$ \\
\hline G & $96.0 \%$ & & $89.3 \%$ \\
\hline \multicolumn{4}{|c|}{ rs10863888 } \\
\hline AA & 50 & NS & 170 \\
\hline$A G$ & 202 & NS & 650 \\
\hline GG & 196 & NS & 754 \\
\hline A & $33.7 \%$ & NS & $31.4 \%$ \\
\hline G & $66.3 \%$ & NS & $68.6 \%$ \\
\hline \multicolumn{4}{|c|}{ rs6540679 } \\
\hline AA & 17 & NS & 81 \\
\hline$A G$ & 171 & NS & 497 \\
\hline $\mathrm{GG}$ & 260 & NS & 982 \\
\hline A & $22.9 \%$ & NS & $21.1 \%$ \\
\hline G & $77.1 \%$ & NS & $78.9 \%$ \\
\hline
\end{tabular}

find a significant association with rs6540679 or rs10863888 in the AAU group and its subgroups (data not shown).

\section{TRAF5 gene implicated in susceptibility to pediatric} uveitis

In total, 458 pediatric uveitis patients were genotyped for three TRAF5 SNPs. The frequencies of the CG genotype and $C$ allele of rs12569232 were significantly decreased in cases compared with normal controls $\left(P_{\mathrm{c}}=3.85 \times 10^{-6}\right.$; OR, 0.420; $\left.P_{\mathrm{c}}=3.0 \times 10^{-8} ; \mathrm{OR}, 0.390\right)$, whereas the GG genotype $\left(P_{\mathrm{c}}=2.41 \times 10^{-7}\right.$; OR, 2.574) and G allele were both increased. As to rs6540679, a decreased frequency of the AA genotype was observed with a $P_{\mathrm{c}}=5.64 \times 10^{-5}$; OR, 0.163. No association was found for rs 10863888 (Table 5). We subsequently compared pediatric uveitis patients with controls on the basis of clinical and laboratory observations. JIA, FFA, ANA, and RF were chosen as our target factors. The results revealed that the frequency of the GG genotype and G allele of rs12569232 was increased in the patient group with microvascular leakage detected by FFA, whereas the CG genotype and $\mathrm{C}$-allele frequencies were decreased compared with healthy controls (Table 6). No association was found for rs 12569232 in patients that had a negative FFA examination. FFA status was not associated with rs10863888 and rs6540679. Furthermore, no significant associations were found when patients were 
Table 4 Genotype and allele frequency analysis between rs12569232/TRAF5 polymorphisms in AAU subgroups and healthy controls

\begin{tabular}{|c|c|c|c|c|}
\hline \multirow{2}{*}{$\begin{array}{l}\text { AAU } \\
\text { Subgroups }\end{array}$} & \multicolumn{4}{|c|}{ Genotype and allele frequency of rs 12569232} \\
\hline & $\mathrm{CC}$ & CG & GG & $\mathrm{C}$ \\
\hline $\mathrm{AAU}^{+} \mathrm{AS}^{+}(n=209)$ & 3 & 14 & 192 & $4.8 \%$ \\
\hline$P_{c}(\mathrm{OR})$ & NS & $1.36 \times 10^{-4}(0.306)$ & $3.10 \times 10^{-4}(2.866)$ & $5.60 \times 10^{-4}(0.417)$ \\
\hline $\operatorname{AAU}^{+} \mathrm{AS}^{-}(n=241)$ & 1 & 14 & 226 & $3.3 \%$ \\
\hline$P_{c}(\mathrm{OR})$ & NS & $5.38 \times 10^{-6}(0.263)$ & $2.0 \times 10^{-6}(3.823)$ & $1.24 \times 10^{-6}(0.285)$ \\
\hline $\mathrm{AAU}^{+} \mathrm{B} 27^{+}(\mathrm{n}=267)$ & 2 & 18 & 247 & $4.1 \%$ \\
\hline$P_{c}(\mathrm{OR})$ & NS & $1.12 \times 10^{-5}(0.308)$ & $7.85 \times 10^{-6}(3.133)$ & $7.48 \times 10^{-6}(0.357)$ \\
\hline $\mathrm{AAU}^{+} \mathrm{B} 27^{-}(n=65)$ & 1 & 3 & 61 & $3.8 \%$ \\
\hline$P_{c}(\mathrm{OR})$ & NS & $0.036(0.206)$ & NS & $0.048(0.332)$ \\
\hline
\end{tabular}

As rs6540679 and rs10863888 did not show a significant association, they are not shown in the subgroups table.

+ , having this feature; -, not having this feature.

subdivided according to their RF or ANA status or whether they had JIA (data not shown).

\section{Discussion}

In the present study, we aimed to determine whether TRAF5 gene polymorphisms were associated with AAU and pediatric uveitis in a Han Chinese population. The results showed that rs12569232 polymorphisms of the TRAF5 gene were associated with both AAU and its subgroups (either accompanied by AS or HLA-B27

Table 5 Genotype and allele-frequency analysis of TRAF5 polymorphisms in pediatric uveitis patients and healthy controls

\begin{tabular}{llll}
\hline SNP & $\begin{array}{l}\text { Pediatric uveitis } \\
(\boldsymbol{n}=\mathbf{4 5 8})\end{array}$ & $\begin{array}{l}\boldsymbol{P}_{\mathbf{c}} \\
\text { (OR) }\end{array}$ & $\begin{array}{l}\text { Control } \\
(\boldsymbol{n}=\mathbf{1 , 6 0 1})\end{array}$ \\
\hline rs12569232 & & 0 & 20 \\
CC & 0 & $3.85 \times 10^{-6}(0.420)$ & 304 \\
CG & 41 & $2.41 \times 10^{-7}(2.574)$ & 1,277 \\
GG & 416 & $3.0 \times 10^{-8}(0.390)$ & $10.7 \%$ \\
C & $4.5 \%$ & & $89.3 \%$ \\
G & $95.5 \%$ & & \\
rs10863888 & & NS & 170 \\
AA & 47 & NS & 650 \\
AG & 220 & NS & 754 \\
GG & 191 & NS & $31.4 \%$ \\
A & $34.3 \%$ & NS & $68.6 \%$ \\
G & $65.7 \%$ & & \\
rs6540679 & & $5.64 \times 10^{-5}(0.163)$ & 81 \\
AA & 4 & NS & 497 \\
AG & 152 & NS & 982 \\
GG & 295 & NS & $21.1 \%$ \\
A & $17.7 \%$ & NS & $78.9 \%$ \\
G & $82.3 \%$ & & \\
\hline
\end{tabular}

positive). The same polymorphism was also associated with pediatric uveitis and, most notably, in the group showing retinal vascular leakage. The frequencies of the CG genotype and C allele of rs12569232 in these test groups were much lower than in the healthy control group, whereas the frequencies of the GG genotype and G allele were significantly higher. A significant association with rs6540679 was found in the pediatric uveitis patients, whereas the frequency of the AA genotype was lower in the patient group compared with controls. No association was found with rs 10863888 either in AAU and its subgroups or in pediatric uveitis and its subgroups. These data suggest that TRAF5 gene polymorphisms may increase the risk for AAU and pediatric uveitis. In the latter group, the association increases the risk for the occurrence of retinal vasculitis.

To our knowledge, this is the first report addressing an association between genetic variants of TRAF5 and uveitis. The similar association of rs12569232 with these two widely differing uveitis entities described in our study may be due to the fact that the eye only has a limited repertoire with which to respond to inflammation and that TRAF5 is possibly involved in this final common intraocular inflammatory pathway. Our group is currently studying the role of TRAF5 in other uveitis entities, such as Vogt-Koyanagi-Harada syndrome and Behçet disease, and data obtained so far confirm the results presented here. As yet, no other studies have shown an association of rs12569232 TRAF5 polymorphisms with disease.

TRAF5, a tumor necrosis factor receptor-associated factor family protein, acts as an activator of the TNFinduced NF- $\mathrm{kB}$ signal pathway $[25,40]$. It is expressed in various organs and peripheral blood [25,41,42]. Overexpression can lead to inflammation and autoimmune disease, and it has also been shown to protect cells from apoptosis $[26,40,43-46]$. In view of the findings mentioned earlier, we hypothesized that TRAF5 may also mediate the 
Table 6 Genotype and allele-frequency analysis of rs12569232/TRAF5 polymorphisms in pediatric uveitis-subgroup patients accompanied by FFA-positive patients

\begin{tabular}{lllllll}
\hline SNP & Subgroup & Genotype & Pediatric uveitis & Controls & $\boldsymbol{P}_{\mathbf{c}}$ & OR (95\% CI) \\
\hline rs12569232 & FFA $+(n=172)$ & GG & 157 & 1,277 & 0.003 & $2.65(1.542-4.573)$ \\
& & CG & 15 & 304 & 0.012 & $0.408(0.237-0.702)$ \\
& CC & 0 & 20 & NS & \\
& G & 329 & 2,858 & $7.68 \times 10^{-3}$ & $2.640(1.555-4.483)$ \\
& & C & 15 & 344 & $7.68 \times 10^{-3}$ & $0.379(0.223-0.643)$ \\
\hline
\end{tabular}

SNP, single-nucleotide polymorphism; OR, odds ratio; $\mathrm{Cl}$, confidence interval; NS, no statistical difference. $\mathrm{P}_{\mathrm{c}}$, Bonferroni corrected $P$ value compared with normal controls. +, having this feature, -, not having this feature.

development of uveitis. The selection of the TRAF5 SNPs was based on previous studies concerning the association with rheumatoid arthritis (see Potter et al. [35], Supplementary Table) [35] and the observed overlap between uveitis and arthritis. We chose rs6540679, rs12569232, and rs10863888 as our target SNPs for TRAF5. We also wanted to include rs7514863, an upstream SNP of TRAF5 shown to be associated with RA [35], but failed to develop a reliable PCR method. Moreover, a TaqMan SNP Genotyping Assay is not yet available for rs7514863.

Our data showed a significant association with polymorphisms of rs6540679 and rs12569232 that were not observed in RA. The reasons for this discrepancy are unclear, but it could point to different roles of TRAF5 in the pathogenesis of arthritis as compared with intraocular inflammation. We furthermore investigated whether these mutations were related not only to the occurrence of disease but also to the disease activity. This was done by analyzing a large number of laboratory parameters for pediatric uveitis, including ANA, RF, ASO (anti-streptolysin “O”), CRP (C-reactive protein), ANCA (anti-neutrophil cytoplasmic antibodies), and ESR (erythrocyte sedimentation rate). In AAU, we analyzed the HLA-B27 status of the patients [47]. Clinical manifestations were analyzed for pediatric uveitis with JIA (both oligoarthritis and polyarthritis), arthritis deformans, retinal vasculitis (determined by FFA test) $[17,48]$, and the presence of AS was estimated for AAU patients. Positivity rates of the laboratory tests were below 15\%, and no associations with TRAF5 gene polymorphisms could be found (data not shown). As mentioned, we did note an association between rs12569232 and the presence of retinal vascular leakage in pediatric uveitis patients. Why rs12569232 is associated with retinal vasculitis in PU and why AAU patients with this mutation do not have retinal vasculitis is an intriguing observation that deserves further study.

Further study also is needed to correlate the TRAF5 genetic data with ophthalmic findings, such as the response to the use of steroids, visual outcome, and recurrence rate. This was not yet possible in the current study, because many of our patients are referred to us by other centers all over China, and the exact medical history concerning treatment and further follow-up of patients is often difficult. Furthermore subdivision into several groups would markedly reduce sample size, thereby reducing the statistical power of the analysis. A future prospective multicenter trial would allow sufficient sample size to address this issue.

We made the following efforts to validate the obtained data. First, the sample sizes of patients and normal controls were large enough to ensure an association analysis. We excluded non-Han patients, and healthy controls were obtained from the same geographic regions as the patients to avoid confounding by genetic ancestry. Furthermore, the diagnosis was performed strictly according to the criteria described previously. Additionally, $10 \%$ of the total samples were randomly selected to undergo direct sequencing so as to validate the results of genotyping with PCR-RFLP and TaqMan SNP Genotyping Assay.

Despite these efforts, some limitations exist in our study. We compared our pediatric uveitis patients with a large group of normal healthy adults, instead of using age-matched controls. The large size of our ethnically matched control group $(n=1,601)$ ensures that we obtained a good representation of the frequency of TRAF5 gene polymorphisms in the Han Chinese population. As this study was performed only in Han Chinese, further research should be done in other ethnic populations to confirm the results. Because our study recruited patients visiting a department of ophthalmology, only uveitis patients were included. Whether the same relation exists between the TRAF5 gene and AS patients without uveitis remains to be studied. We studied only the relation with three TRAF5 SNPs, and further studies, including other SNPs of TRAF5, must be performed. Whether the TRAF5 polymorphisms described here play a functional role is not yet clear, and further functional and association studies are needed to address this issue. A recent study by our group showed that healthy control carriers of the GG genotype in SNP rs6540679/TRAF5 had a higher TRAF5 mRNA expression level and enhanced TNF- $\alpha$ and IL- 6 secretion compared with AA and AG carriers (unpublished data). We were not able to find an effect of the various rs12569232 TRAF5 genotypes on TRAF5 mRNA expression by stimulated peripheral blood mononuclear cells (data not shown), 
and we cannot exclude that the association found reflects an association in linkage disequilibrium with the causative locus. It should also be noted that the GG phenotype of rs12569232 is quite common in China and that TRAF5 is only one gene in a multihit process involving a large number of genes involved in the regulation of an inflammatory immune response, finally leading to the expression of clinical uveitis.

\section{Conclusion}

Our study investigated the association of TRAF5 with two common forms of uveitis (AAU and pediatric uveitis) and identified rs12569232 polymorphisms were associated with AAU and its subgroups (accompanied by either AS or HLA-B27 positive). The same mutation was also found in pediatric uveitis and significantly in the group showing retinal vascular leakage, which suggests that rs12569232/ TRAF5 may play a role in the development of retinal vasculitis.

\section{Abbreviations}

AAU: Acute anterior uveitis; ANA: Anti-nuclear antibody; AS: Ankylosing spondylitis; FFA: Fundus fluorescein angiography; HWE: Hardy-Weinberg equilibrium; JA: Juvenile idiopathic arthritis; OR: Odds ratio; PCR-RFLP: Polymerase chain reaction-restriction fragment length polymorphism; RF: Rheumatoid factor; SNP: Single-nucleotide polymorphism; TNF: Tumor necrosis factor; TRAF5: TNF receptor-associated factor 5.

\section{Competing interests}

No conflicting relation exists for any author, and the authors have no proprietary or commercial interest in any materials discussed in this article.

\section{Authors' contributions}

QX was listed as XQ, LC was listed as CL, JF was listed as FJ, SH was listed as HSP, PY was listed as YPZ, and AK was listed as AK. LW, LB, YL, YZ were listed as $W L, B L, L Y J$ and $Z Y$, respectively. $X Q$ carried out the gene polymorphism studies, including collecting DNA samples, extracting DNA, genotyping and analyzing the data, and also drafted the manuscript. $\mathrm{CL}$ participated in the whole direct sequencing and arrangement of clinical data, and partly participated in DNA sample collection and genotyping. FJ carried out uveitis screening protocols, such as ANA, RF, and FFA. HSP participated in the design of PCR primers and statistical analysis. YPZ conceived of the study and participated in its design and coordination. AK helped to revise the manuscript. WL, BL, LYJ, and ZY carried out DNA sample collection, extraction, and patients' clinical symptoms gathering. All authors read and approved the final manuscript.

\section{Acknowledgements}

The samples of patients and healthy controls were partially collected in ZhongShan Ophthalmic Center, Sun Yat-sen University. Thanks to Ms Hongyan Zhou and Mr Xiangkun Huang for their assistance in sample collection and technical support. Thanks to all donors enrolled in the present study. This work was supported by National Basic Research Program of China (973 Program) (2011CB510200), Key Project of Natural Science Foundation (81130019), Clinic Key Project of Ministry of Health, Basic Research program of Chongqing, Chongqing Key Laboratory of Ophthalmology (CSTC, 2008CA5003), Key Project of Health Bureau of Chongqing(2012-1-003) and Fund for PAR-EU Scholars Program. The funders had no role in study design, data collection and analysis, the decision to publish, or the preparation of the manuscript.

\section{Author details}

${ }^{1}$ The First Affiliated Hospital of Chongqing Medical University, Chongqing Key Laboratory of Ophthalmology and Chongqing Eye Institute, Chongqing 400016, PR China. ${ }^{2}$ University Eye Clinic Maastricht, Maastricht, The Netherlands.
Received: 11 May 2013 Accepted: 23 August 2013

Published: 11 September 2013

\section{References}

1. Yang P, Zhang Z, Zhou H, Li B, Huang X, Gao Y, Zhu L, Ren Y, Klooster J, Kijlstra A: Clinical patterns and characteristics of uveitis in a tertiary center for uveitis in China. Curr Eye Res 2005, 30:943-948.

2. Monnet D, Breban M, Hudry C, Dougados M, Brézin AP: Ophthalmic findings and frequency of extraocular manifestations in patients with HLA-B27 uveitis: a study of 175 cases. Ophthalmology 2004, 111:802-809.

3. Wakefield D, Chang Z, Maconochie S, el-Asrar AA, McCluskey P, Amjadi S: What is new HLA-B27 acute anterior uveitis? Ocul Immunol Inflamm 2011, 19:139-144.

4. Gran J, Skomsvoll J: The outcome of ankylosing spondylitis: a study of 100 patients. Rheumatology 1997, 36:766-771.

5. Chang JH, McCluskey PJ, Wakefield D: Acute anterior uveitis and HLA-B27. Surv Ophthalmol 2005, 50:364-388.

6. Braun J, Baraliakos X, Listing J, Sieper J: Decreased incidence of anterior uveitis in patients with ankylosing spondylitis treated with the anti-tumor necrosis factor agents infliximab and etanercept. Arthritis Rheum 2005, 52:2447-2451.

7. Rashid T, Ebringer A: Ankylosing spondylitis is linked to Klebsiella: the evidence. Clin Rheumatol 2007, 26:858-864.

8. Feltkamp TE, Ringrose $\mathrm{JH}$ : Acute anterior uveitis and spondyloarthropathies. Curr Opin Rheumatol 1998, 10:314-318.

9. Wakefield D, Montanaro A, Cluskey P: Acute anterior uveitis and HLA-B27. Surv Ophthalmol 1991, 36:223-232.

10. Gonzalez-Roces S, Alvarez M, Gonzalez S, Dieye A, Makni H, Woodfield D, Housan L, Konenkov V, Abbadi M, Grunnet N: HLA-B27 polymorphism and worldwide susceptibility to ankylosing spondylitis. Tissue Antigens 1997, 49:116-123.

11. Brewerton DA, Hart FD, Nicholls A, Caffrey M, James DC, Sturrock RD: Ankylosing spondylitis and HL-A 27. Lancet 1973, 1:904-907.

12. Lopez-Larrea C, Sujirachato K, Mehra N, Chiewsilp P, Isarangkura D, Kanga U, Dominguez O, Coto E, Pena M, Setien F: HLA-B27 subtypes in Asian patients with ankylosing spondylitis: evidence for new associations. Tissue Antigens 1995, 45:169-176.

13. Jaakkola E, Herzberg I, Laiho K, Barnardo MC, Pointon JJ, Kauppi M, Kaarela K, Tuomilehto-Wolf E, Tuomilehto J, Wordsworth BP, Brown MA: Finnish HLA studies confirm the increased risk conferred by HLA-B27 homozygosity in ankylosing spondylitis. Ann Rheum Dis 2006, 65:775-780.

14. Cunningham J, Emmett T: Uveitis in children. Ocul Immunol Inflamm 2000, 8:251-261.

15. Benezra D, Cohen E, Maftzir G: Patterns of intraocular inflammation in children. Bull Soc Belge Ophtal 2001, 279:35-38.

16. Smith JA, Mackensen F, Sen H, Leigh JF, Watkins AS, Pyatetsky D, Tessler HH, Nussenblatt RB, Rosenbaum JT, Reed GF: Epidemiology and course of disease in childhood uveitis. Ophthalmology 2009, 116:1544-1551. e1541.

17. Tugal-Tutkun I: Pediatric uveitis. J Ophthal Vis Res 2011, 6:259-269.

18. Reveille JD: Recent studies on the genetic basis of ankylosing spondylitis. Curr Rheumatol Rep 2009, 11:340-348.

19. Chang JH, Hampartzoumian T, Everett B, Lloyd A, McCluskey PJ, Wakefield D: Changes in Toll-like receptor (TLR)-2 and TLR4 expression and function but not polymorphisms are associated with acute anterior uveitis. Invest Ophthalmol Vis Sci 2007, 48:1711-1717.

20. Kuo N-W, Lympany PA, Menezo V, Lagan AL, John S, Yeo TK, Liyanage S, du Bois RM, Welsh KI, Lightman S: TNF - 857T, a genetic risk marker for acute anterior uveitis. Invest Ophthalmol Vis Sci 2005, 46:1565-1571.

21. Ahad MA, Missotten T, Abdallah A, Lympany PA, Lightman S: Polymorphisms of chemokine and chemokine receptor genes in idiopathic immune-mediated posterior segment uveitis. Mol Vision 2007 13:388.

22. Davidson SI, Wu X, Liu Y, Wei M, Danoy PA, Thomas G, Cai Q, Sun L, Duncan E, Wang N, Yu Q, Xu A, Fu Y, Brown MA, Xu H: Association of ERAP1, but not IL23R, with ankylosing spondylitis in a Han Chinese population. Arthritis Rheum 2009, 60:3263-3268.

23. Sung $I H$, Kim TH, Bang SY, Kim TJ, Lee B, Peddle L, Rahman P, Greenwood CM, Hu P, Inman RD: IL-23R polymorphisms in patients with ankylosing spondylitis in Korea. J Rheumatol 2009, 36:1003-1005. 
24. Pimentel-Santos FM, Ligeiro $D$, Matos $M$, Mourão $A F$, Sousa E, Pinto $P$, Ribeiro A, Sousa M, Barcelos A, Godinho F, Cruz M, Fonseca JE, Guedes-Pinto H, Trindade H, Evans DM, Brown MA, Branco JC: Association of IL23R and ERAP1 genes with ankylosing spondylitis in a Portuguese population. Clin Exp Rheumatol 2009, 27:800-806.

25. Nakano $\mathrm{H}$, Oshima $\mathrm{H}$, Chung W, Williams-Abbott L, Ware CF, Yagita $\mathrm{H}$, Okumura K: TRAF5, an activator of NF-KB and putative signal transducer for the lymphotoxin- $\beta$ receptor. J Biol Chem 1996, 271:14661-14664.

26. Akiba H, Nakano H, Nishinaka S, Shindo M, Kobata T, Atsuta M, Morimoto C, Ware CF, Malinin NL, Wallach D: CD27, a member of the tumor necrosis factor receptor superfamily, activates NF-KB and stress-activated protein kinase/c-Jun N-terminal kinase via TRAF2, TRAF5, and NF-KB-inducing kinase. J Biol Chem 1998, 273:13353-13358.

27. Song $H Y$, Régnier $C H$, Kirschning $C J$, Goeddel DV, Rothe M: Tumor necrosis factor (TNF)-mediated kinase cascades: bifurcation of nuclear factor-KB and c-jun N-terminal kinase (JNK/SAPK) pathways at TNF receptorassociated factor 2. Proc Natl Acad Sci U S A 1997, 94:9792-9796.

28. Varsani H, Patel A, Van Kooyk Y, Woo P, Wedderburn L: Synovial dendritic cells in juvenile idiopathic arthritis (JIA) express receptor activator of NF-KB (RANK). Rheumatology 2003, 42:583-590.

29. Roman-Blas JA, Jimenez SA: Targeting NF-KB: a promising molecular therapy in inflammatory arthritis. Int Rev Immunol 2008, 27:351-374.

30. Kim HR, Kim HY, Lee SH: Elevated serum levels of soluble receptor activator of nuclear factors-KB ligand (sRANKL) and reduced bone mineral density in patients with ankylosing spondylitis (AS). Br Soc Rheumatol 2006, 45:1197-1200.

31. Yang C-H, Fang IM, Lin C-P, Yang C-M, Chen M-S: Effects of the NF-KB inhibitor pyrrolidine dithiocarbamate on experimentally induced autoimmune anterior uveitis. ARVO 2005, 46:1339-1347.

32. Aktas O, Prozorovski T, Smorodchenko A, Savaskan NE, Lauster R, Kloetze P-M, Infante-Duarte C, Brocke S, Zipp F: Green tea epigallocatechin-3-gallate mediates T cellular NF-kB inhibition and exerts neuroprotection in autoimmune encephalomyelitis. Am Assoc Immunol 2004, 173:5794-5800.

33. Kitamei H, Iwabuchi K, Namba K, Yoshida K, Yanagawa Y, Kitaichi N, Kitamura M, Ohno S, Ono K: Amelioration of experimental autoimmune uveoretinitis (EAU) with an inhibitor of nuclear factor-KB (NF-KB), pyrrolidine dithiocarbamate. Soc Leukocyte Biol 2006, 79:1193-1201.

34. Roman-Blas JA, Jimenez SA: Targeting NF-KB: a promising molecular therapy in inflammatory arthritis. Informa UK Ltd UK 2008, 27:351-374.

35. Potter C, Eyre S, Cope A, Worthington J, Barton A: Investigation of association between the TRAF family genes and RA susceptibility. Ann Rheum Dis 2007, 66:1322-1326.

36. van der Linden S, Valkenburg HA, Cats A: Evaluation of diagnostic criteria for ankylosing spondylitis: a proposal for modification of the New York criteria. Arthritis Rheum 1984, 27:361-368.

37. Miettinen $\mathrm{R}$, Saari M: Clinical characteristics of familial acute anterior uveitis. Can J Ophthalmol 1977, 12:1-3.

38. Rothova A, van Veenedaal WG, Linssen A, Glasius E, Kijlstra A, de Jong PT: Clinical features of acute anterior uveitis. Am J Ophthalmol 1987, 103:137-145.

39. Chen F, Hou S, Jiang Z, Chen Y, Kijlstra A, Rosenbaum JT, Yang P: CD40 gene polymorphisms confer risk of Behcet's disease but not of Vogt-Koyanagi-Harada syndrome in a Han Chinese population. Rheumatology (Oxford) 2012, 51:47-51

40. Tada K Okazaki T, Sakon S, Kobarai T, Kurosawa K, Yamaoka S, Hashimoto $H$, Mak TW, Yagita H, Okumura K: Critical roles of TRAF2 and TRAF5 in tumor necrosis factor-induced NF-KB activation and protection from cell death. J Biol Chem 2001, 276:36530-36534.

41. Zapata JM, Krajewska M, Krajewski S, Kitada S, Welsh K, Monks A, McCloskey N, Gordon J, Kipps TJ, Gascoyne RD: TNFR-associated factor family protein expression in normal tissues and lymphoid malignancies. J Immunol 2000, 165:5084.

42. Au PY, Yeh WC: Physiological roles and mechanisms of signaling by TRAF2 and TRAF5. Adv Exp Med Biol 2007, 597:32-47.

43. So T, Salek-Ardakani S, Nakano H, Ware CF, Croft M: TNF receptor-associated factor 5 limits the induction of Th2 immune responses. J Immunol 2004, 172:4292-4297.

44. Rojas-Cartagena C, Flores I, Appleyard CB: Role of tumor necrosis factor receptors in an animal model of acute colitis. Cytokine 2005, 32:85-93.
45. Snell $L M, L i n G H, M c P h e r s o n ~ A J$, Moraes $T J$, Watts $T H: T$-cell intrinsic effects of GITR and 4-1BB during viral infection and cancer immunotherapy. Immunol Rev 2011, 244:197-217.

46. Dolcino M, Cozzani E, Riva S, Parodi A, Tinazzi E, Lunardi C, Puccetti A: Gene expression profiling in dermatitis herpetiformis skin lesions. Clin Dev Immunol 2012, 2012:198956.

47. BenEzra D, Cohen E, Maftzir G: Uveitis in children and adolescents. Br J Ophthalmol 2005, 89:444-448.

48. Rosenberg KD, Feuer WJ, Davis JL: Ocular complications of pediatric uveitis. Ophthalmology 2004, 111:2299-2306.

\section{doi:10.1186/ar4293}

Cite this article as: Xiang et al:: TNF receptor-associated factor 5 gene confers genetic predisposition to acute anterior uveitis and pediatric uveitis. Arthritis Research \& Therapy 2013 15:R113.

\section{Submit your next manuscript to BioMed Central and take full advantage of:}

- Convenient online submission

- Thorough peer review

- No space constraints or color figure charges

- Immediate publication on acceptance

- Inclusion in PubMed, CAS, Scopus and Google Scholar

- Research which is freely available for redistribution 